\title{
SAĞLIK HİZMETLERINNDE HASTA ODAKLI YAKLAŞIM: HASTA KATILIMI
}

Okan ÖZKAN ${ }^{1}$

Atıf/C: Özkan, Okan (2017). Sağlık Hizmetlerinde Hasta Odaklı Yaklaşım: Hasta Katılımı. Hitit Üniversitesi Sosyal Bilimler Enstitüsü Dergisi, Yıl 10, Sayı 2, Aralık 2017, ss.1759-1770

Özet: Hasta katılımı kavramı; bireyin hastalığ önlemek, yönetmek ve tedavi etmek amacıyla sağlık profesyonellerinin bilgi ve tavsiyelerini kendi ihtiyaç ve tercihleriyle uyumlu hale getirdiği bir süreç olarak tanımlanmaktadır ve bu yaklaşımın gerek birey gerekse toplum sağlığının geliştirilmesine yönelik olumlu katkıları bulunmaktadır. Hasta katılımı yaklaşımı, bireyin sağlık hizmetlerindeki rolünü aktif hale getirerek sağlık hizmetleri ve tedavi sürecinin geliştirilmesini, daha iyi sağlık sonuçlar elde edilmesini, sağlık hizmeti maliyetlerinin azaltılmasını ve daha etkin sağlık politikalarının belirlenmesini sağlamaktadır. Bu çalışmada hasta katılımı kavramına, sağlık hizmetlerindeki önemine, hasta katılım süreci aşamalarına, hasta katılımı ile hasta güvenliği ilişkisine ve hasta katılımı yaklaşımının avantajları ve zorluklarına değinilmiştir. Bu çalışmayla hasta katılımı kavramı hakkında bilgi vermek, gerek sağlık profesyonelleri gerekse de karar vericilerde konu ile ilgili farkındalık yaratmak amaçlanmiştır.

Anahtar Kelimeler: Hasta Güvenliği, Hasta Katılımı, Sağlık Hizmetleri

\section{Patient-Oriented Approach in Health Services: Patient Engagement}

Citation/@: Özkan, Okan. (2017). Patient-Oriented Approach in Health Services: Patient Engagement, Hitit University Journal of Social Sciences Institute, Year 10, Issue 2, December 2017, pp.1759-1770

Abstract: Patient engagement concept is defined as a process by which health professionals make the information and recommendations of the individual compatible with their own needs and preferences in order to prevent, manage and treat the disease, and this approach has positive contributions to the improvement of both the individual and the community health. The patient engagement approach enables the individual to improve his/her role in health services, thereby improving health services and the treatment process, achieving better health outcomes, reducing health care costs and determining more effective health policies. In this study, the concept of patient engagement, the importance in health services, patient engagement process stages, the relation of patient engagement with patient safety and the advantages and difficulties of patient engagement approach are mentioned. With this study, it is aimed to give information about the concept of patient engagement and to provide awareness about the subject to health professionals and decision makers.

Keywords: Patient Safety, Patient Engagement, Health Services

Makale Geliş Tarihi: 28.02.2017/ Makale Kabul Tarihi: 01.11.2017

1 Arş. Gör., Ankara Üniversitesi, Sağlık Bilimleri Fakültesi, Sağlık Yönetimi Bölümü, e-posta:

okan3093@gmail.com 


\section{GİRIŞ}

Son yıllarda sağlik sektöründe yaşanan değişimler, hasta merkezli hizmet anlayışını ön plana çıkarmış ve sağlık hizmetlerinde hastaların daha aktif bir rol alması gerektiği sonucunu doğurmuştur. Bu kapsamda hastaların sağlıklarıyla ilgili karar verme sürecine katılarak sağlık profesyonelleriyle işbirliği yapmasının gerek birey gerekse toplum sağlığına olumlu katkıları olduğu görülmektedir.

Bir hastanın sağlığını geliştirmeye yönelik faaliyetleri tanımlamak için hasta aktivasyonu, hasta özyeterliği, kişisel bakım ve özyönetim gibi birçok terim kullanılmıştır. Günümüzde bu terimler yerine hasta katılımı kavramı kullanılmaya başlanmıştır (Wasson ve Coleman, 2014: 9). Hasta katılımı, sağlık alanında yapılan araştırmalara bireylerin aktif katılımını sağlayarak klinik uygulamaların geliştirilmesinde olumlu katkılar sunması ve yapılan araştırmanın değerini artırması açısından önemli bir role sahiptir. (Domecq vd., 2014; Sullivan ve Goldman, 2011: 400).

Hasta katılımı kavramı hakkında yurtdışında birçok çalışma yapılmasına rağmen bu konuda Türkiye'de yapılmış fazla çalışma bulunmamaktadır. Bu çalışma ile hasta katılımı kavramı hakkında bilgi vermek, gerek sağlık profesyonelleri gerekse de karar vericilerde konu ile ilgili farkındalık yaratmak ve literatüre katkıda bulunmak amaçlanmaktadır.

\section{SAĞLIK HİZMETLERINNDE HASTA KATILIMI KAVRAMI}

Hasta katılımı "bireylerin mevcut sağlık hizmetlerinden en büyük faydayı elde edebilmek için atması gereken adımlar" olarak tanımlanabilir. Bu tanım, sağlık profesyonelleri ve kurumsal politikalardan ziyade bireylerin sağlık sonuçları açısından kritik ve proksimal olan sağlık hizmetleri ile ilişkili davranışlarına odaklanmaktadır (Center for Advancing Health, 2010: 2). Bir başka tanıma göre hasta katılımı; hastalar, kamu ve sağlık profesyonelleri arasındaki ortaklık süreci olarak tanımlanmaktadır (Ocloo ve Matthews, 2016: 627).

Hastaların kendi sağlık hizmetlerine katılımını sağlamak yükselişte olan bir trenddir. Amerika'da bulunan Tip Ensitüsü (Institute of Medicine), bireylere gerekli tıbbi ve klinik bilgiye erişim fırsatı sunulmasını ve böylece sağlık hizmeti kararları verirlerken 'kontrol kaynağı' olmalarının sağlanmasını tavsiye etmektedir. Hasta katılımının artırılmasıyla hastaların daha yüksek bir tatmin ve daha iyi sağlık sonuçları elde edeceğine inanılmaktadır (Prey 
vd., 2014: 742). Bu kapsamda yapılan bir çalışmada, katılım sağlayan hastaların tatmin düzeyinin daha yüksek olduğu, kendi sağllk hizmetlerini daha iyi anladıkları, sağlığı iyileştiren davranışları daha çok benimsedikleri görülmüş ve hastaların doktorlarına güvenlerinin arttığı ve sağlık çıktılarının iyileştiği sonucuna ulaşılmıştır (Tang ve Newcomb, 1998).

Hasta katılımı yaklaşımına bir başka bakış açısı ise Maslow'un İhtiyaçlar Hiyerarşisi modeli temel alınarak yapılmaktadır. Bu kapsamda gerçek anlamda katılım sağlamış olan hastalar kendi sağlıkları için pozitif tercihler yapmakta ve sistemin bir tedavi sistemi yerine önleme kültürüne doğru ilerlemesini sağlamaktadır (Armstrong, 2014).

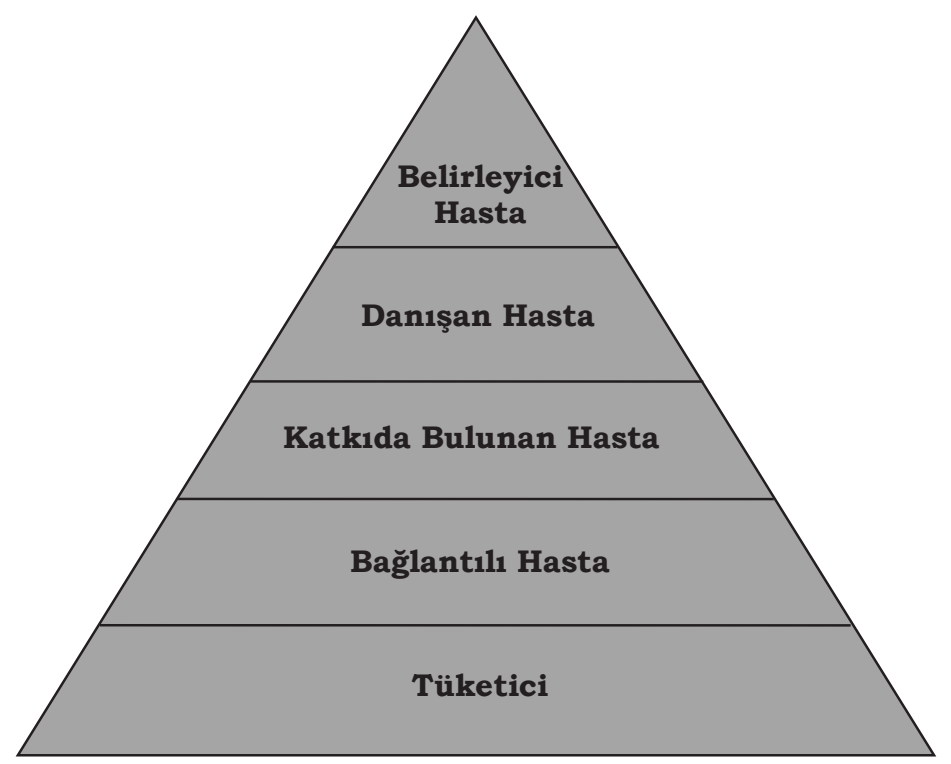

Şekil 1: Hasta Kat1lım Piramidi (Armstrong, 2014)

Şekil 1'de görüldüğü gibi piramit hastaların sağlık hizmetlerinin tüketicileri olarak kabul etmesiyle başlamaktadır. Bir sonraki aşamada ise hastalarla iki yönlü elektronik bilgi akışı sağlanarak katılım süreci başlayabilir. Hastalar için daha kolay olan artırılmış erişim ise üçüncü düzeyde ortaya çıkmaktadır. Katkıda bulunan hasta olarak tanımlanan bu düzeyde hastalar, sağlık bilgilerine erissmenin yanı sıra kendi sağlık durumlarının belirlenmesine de (alerjileri, aldıkları ilaçlar vb.) katkıda bulunmaktadırlar. Danışan hasta aşamasında ise, hastalar aktif olarak kendi sağlık hizmeti ekibine sorular soran, eğitim amaçlı bilgi isteyen kişiler rolünü 
üstlenmektedirler. Piramidin zirvesinde ise "Görev Belirleyen Hasta" yer almaktadır. Kişinin kendi sağlığını yönetmek ve sağlık hedefleri belirlemek için sağlık hizmeti sunucularıyla işbirliği yaptığı aşamadır. Bu noktada hasta kendi sağlığ ile ilgili tam bir katılım sağlamış olur (Armstrong, 2014).

Hasta katılımı, sağlık bakımının temel üç hedefinin (sağlık bakım kalitesinin artması, toplum sağlığının geliştirilmesi ve maliyetlerin azaltılması) gerçekleşmesi açısından gerekli bir strateji olarak değerlendirilmektedir. Bu kapsamda etkili ve verimli bir hasta katılımı için aşağıda belirtilen hususların gerçekleşmesi gerekmektedir (Athenahealth, 2014: 2):

- Hastaların kendilerinin ve aile üyelerinin sağlı ve bakımını yönetebilecek bilgi, beceri, yetenek ve istekliliklerinin olması

- Sağlık kurumunun hastaların katılımını öncelikli gören ve destekleyen kültüre sahip olması

- Olumlu sağlık çıktılarını tasarlamak, yönetmek ve elde etmek için hastalar ve hizmet sunucular arasında aktif işbirliği

Hasta katılımı bir sağlık hizmeti modeli olarak ortaya çıkmıştır. Hasta merkezli tedavi, hasta katılımı ve etkinliği ile ilgili literatürün incelenmesi sonucu ortaya çıkan model Şekil 2'de görülmektedir (Pelletier ve Stichler, 2013: 53).

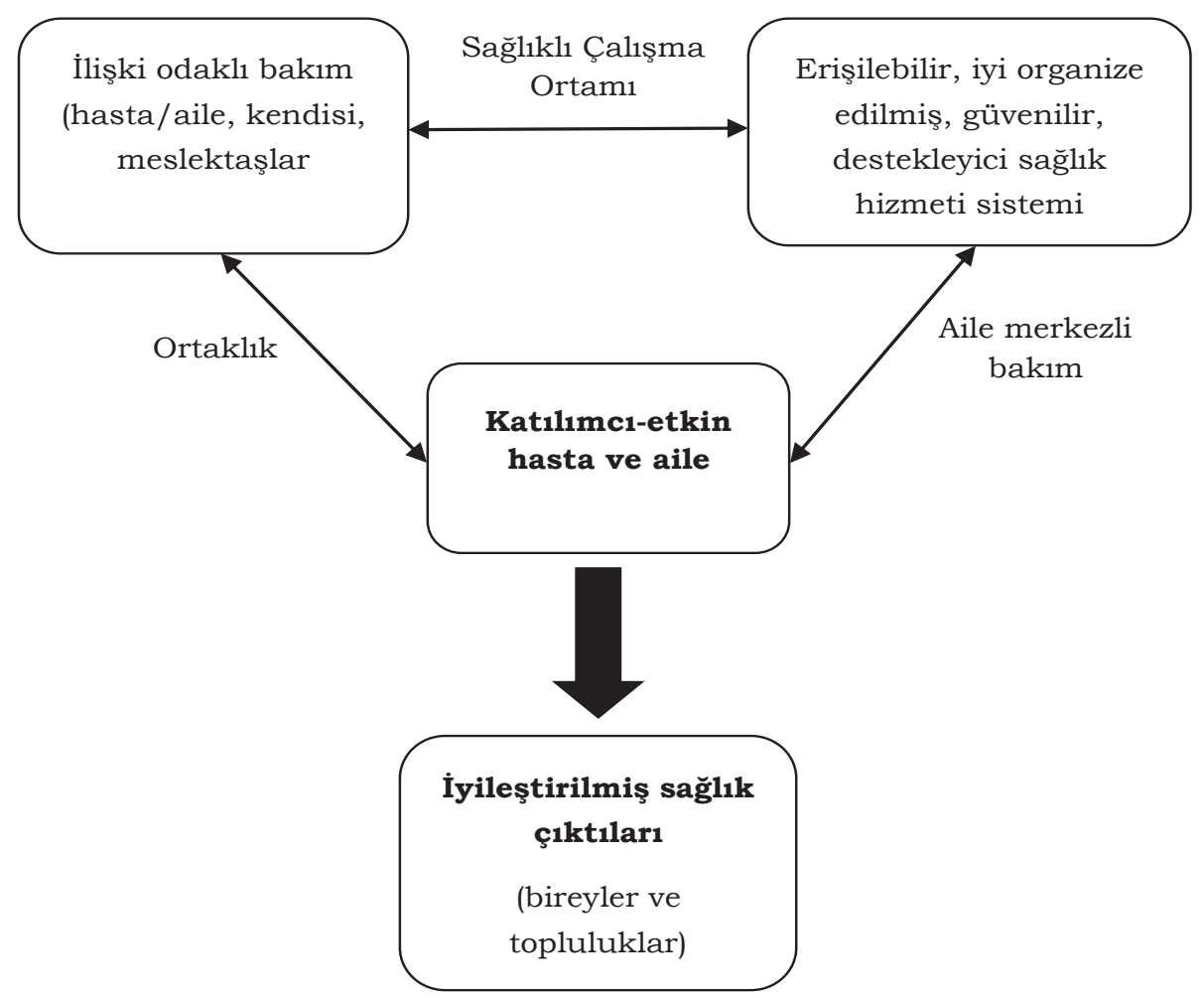


Şekil 2: Hasta Katılımı ve Tedavi Etkinlik Modeli (Pelletier ve Stichler, 2013: 53)

$\mathrm{Bu}$ modelin merkezinde katılım sağlamış, aktif hasta ve ailesi bulunmaktadır. Sağlıklı bir iş ortamı yoluyla ilişkiye dayalı sağlık hizmeti erişilebilir, iyi organize olmuş, güvenilir ve destekleyici sağlık hizmeti sistemini garanti edebilir. Ortaklık ve aile merkezli sağlık hizmeti yoluyla aktif bir hasta kendi sağlık hizmetlerine aktif olarak dahil olan bir kişi olarak ortaya çıkar ve bu da sağlık hizmeti çıktılarının iyileşmesi ile sonuçlanır (Pelletier ve Stichler, 2013: 53).

Hastaların karar verme sürecine katılımlarıyla ilgili hastaların rolleri, ne yaptıkları ve ideolojik dinamikler çerçevesinde geliştirilen dört model bulunmaktadır (Forbat vd., 2009: 2548). Hasta katılımı modelleri Tablo 1'de görülmektedir.

Tablo 1. Hasta Kat1lımı Modelleri

\begin{tabular}{|l|l|l|}
\hline \multicolumn{1}{|c|}{ Kim } & \multicolumn{1}{|c|}{ Ne Yapıyor? } & \multicolumn{1}{|c|}{ İdeolojik Dinamikler } \\
\hline $\begin{array}{l}\text { Tüketici olarak } \\
\text { hasta }\end{array}$ & $\begin{array}{l}\text { Hizmet satın alımı veya } \\
\text { tercihi }\end{array}$ & $\begin{array}{l}\text { Serbest piyasa } \\
\text { ekonomisi }\end{array}$ \\
\hline $\begin{array}{l}\text { Vatandaş olarak } \\
\text { hasta }\end{array}$ & $\begin{array}{l}\text { Politika ve hizmet } \\
\text { planlaması }\end{array}$ & Sosyal-demokratik \\
\hline Ortak olarak hasta & Bakım uygulaması & Deneyimsel bilgi \\
\hline $\begin{array}{l}\text { Araştırmacı olarak } \\
\text { hasta }\end{array}$ & Birlikte araştırma & $\begin{array}{l}\text { Serbestlik ve } \\
\text { güçlendirme }\end{array}$ \\
\hline
\end{tabular}

Kaynak: Forbat vd., 2009: 2548

Tablo 1'de görüldüğü gibi hasta katılımı yaklaşımı farklı ideolojiler ve hastaların çok farklı şekillerde konumlandırılmasıla geniş ve bazen de karmaşıktır. Katılımın bir politika ve literatürde ifade edilme şekli içerik ve ideolojik yönelime bağlı olarak hastaları tüketici, vatandaş, ortak ve araştırmacı şeklinde konumlandırmıştır. Tüketici ve vatandaş olarak hastalar politika ve hizmet planlama sürecinin geliştirilmesine dahil olur; tüketici ve ortak olarak nasıl ve nerede tedavi göreceklerini belirleyerek kendi sağlık hizmeti uygulamalarına dahil olurlar ve araştırmacı olarak da sağlık araştırmalarına katılırlar (Forbat vd., 2009: 2548). 


\section{HASTA KATILIMI SÜRECI்}

Hasta katılımı, tüm tedavi seçeneklerinin olası faydaları ve zararları üzerine mevcut en iyi bilimsel bulguların yanı sıra hastanın mevcut değer yargıları ve tercihlerinin hesaba katıldığ ve hastalar ile sağlık hizmet sunucularının birlikte kararlar aldığı bir süreçtir (Gee ve Corry, 2012: 996). Hasta katılımı, hasta ile sağlayıcı arasında ne kadar bilgi akışı olduğu, hastanın sağlık ile ilgili kararlarda ne kadar aktif bir role sahip olduğu ve hastanın sağlık organizasyonu kararları ve politika oluşturulması ile ne kadar yakından ilişkili olduğu ile karakterize edilebilir. Katılım süreci danışmadan ortaklık veya paylaşılan liderliğe kadar uzanabilmektedir. Sürecin en alt düzeyinde hastalar katılım sağlamaktadır ancak sınırlı güç veya karar verme yetkisine sahiptir. Hizmet sunucular, kurumlar ve sistemler kendi gündemlerini tanımlar ve daha sonra hastanın vereceği bilgiyi beklerler. Bilgi önce hastalara gider ve daha sonra da sisteme geri dönmektedir. Sürecin orta düzeyinde hastalar hekimin ve sağlı hizmetleri sağlama sisteminin notları gibi kayıtlarına doğrudan erişime sahiptir ancak katkıda bulunamaz veya bilgiyi düzeltemezler. Buna karşın sürecin ortaklık ucunda hastalar kendi kayıtlarına doğrudan erişime sahiptir ve hekimin ve sistemin notlarını görebilir, bilgi ekleyebilir veya bilgiyi düzeltebilirler. Bu kayıtlar, hem hasta hem de hekim bakış açısından sağlık hizmeti deneyiminin tümünü yansıtabilirler ve ilgili bilginin dahil edilmesiyle sağlı hizmeti kararları işbirliği içerisinde verilebilir. Paylaşılan güç ve sorumluluk ile birlikte daha iyi ve daha hasta odaklı sonuçlar elde etme imkanı da artmaktadır. Sürecin en üst düzeyinde ise katılım paylaşılan güç ve sorumluluk ile karakterize edilmektedir ve hastalar gündem belirleme ve karar verme süreçlerinde aktif ortaklar halini almaktadırlar. Bilgi akışı katılım süreci yoluyla iki yönde gerçekleşir ve karar verme sorumluluğu paylaşılır (Carman vd., 2013: 224).

Katılım sürecine yönelik olarak geliştirilen "Sağlık ve Sağlık Hizmetlerinde Hasta ve Aile Katılımı için Çok Boyutlu bir Kuramsal Çerçeve” adlı model Şekil 3’te görülmektedir. İlgili modelde doğrudan sağlık bakımı, örgütsel tasarım ve yönetişim ve politika belirleme olmak üzere katılımın üç farklı düzeyi bulunmaktadır (Carman vd., 2013: 225). 


\section{Katılım Süreci}

\section{Katilım Düzeyleri}

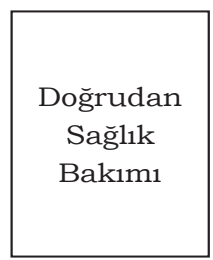

\begin{tabular}{|c|}
\hline \\
Örgütsel \\
Tasarım \\
ve \\
Yönetişim \\
\end{tabular}



\section{Danışma}

Hastalar tanı
hakkında bilgi
alır.

\begin{tabular}{|l|}
\hline Kurum \\
hastaları \\
sağlık \\
hizmetleri \\
deneyimleri \\
bakımından \\
değerlendirir.
\end{tabular}

Kamu

kuruluşu, bir sağllk konusu ile ilgili fikir almak için odak grupları yönetir.

\section{Katılım}

\section{Ortaklik veya \\ Paylaşılan \\ Liderlik}

\begin{tabular}{|c|c|}
\hline $\begin{array}{l}\text { Hastalara tedavi } \\
\text { planları } \\
\text { hakkındaki } \\
\text { tercihleri } \\
\text { sorulur. }\end{array}$ & $\begin{array}{l}\text { Hastaların } \\
\text { tercihleri, tıbbi } \\
\text { bulgular ve klinik } \\
\text { görüşe bağlı } \\
\text { olarak tedavi } \\
\text { kararları verilir. }\end{array}$ \\
\hline
\end{tabular}

Hastane, hastay1 danışman veya danışma kurulu üyesi olarak sürece dahil eder.



Finansman kararları verilmesi için hastaların araştırma öncelikleri hakkındaki tavsiyeleri kamu kuruluşu tarafindan kullanılır.

\section{Katılımı Etkileyen Faktörler:}

- Hasta (Hastanın rolü hakkındaki inançları, Sağlık Okuryazarlığı, Eğitim)

- Örgüt (Politikalar ve Uygulamalar, Kültür)

- Toplum (Sosyal Normlar, Düzenlemeler, Politika)

Şekil 3: Sağlık ve Sağlık Hizmetlerinde Hasta ve Aile Katılımı için Çok Boyutlu Bir Kuramsal Çerçeve (Carman vd., 2013: 225) 
Şekil 3'te görüldüğü gibi, hasta katılımının etkinliği arttıkça hastaların tedavi planlarının belirlenmesinde, hasta güvenliğinin sağlanmasında ve sağlık politikalarının uygulanmasında aktif bir rol almaktadır. Hasta katılımı sürecine hasta, örgüt ve topluma ilişkin faktörlerin olumlu veya olumsuz yönde önemli etkileri bulunmaktadır.

\section{HASTA KATILIMI VE HASTA GÜVENLİĞİ İLISSKİSi}

Sağlık hizmetlerinin sunumu esnasında bireylerin maruz kalabileceği zararı önlemek amacıyla sağlık kurumları ve bu kurumlardaki çalışanlar tarafından alınan önlemlerin tamamı hasta güvenliği olarak tanımlanmaktadır (Ardahan ve Alp, 2015: 85). Etkili ve başarılı bir hasta güvenliği uygulamaları için hastaların da bu sürece aktif katılımları gerekmektedir.

Hastaların hasta güvenliğindeki katılımı, hata önleme stratejilerinde hastaların farkındalığı ve katılımını artırmayı amaçlamaktadır. Hastaların, hata önleme stratejilerine aktif katılımının nasıl sağlanacağını anlayabilmek için hasta katılımı, hasta güvenliği ve güvenlik kültürü üzerine yapılan çalışmaların incelenmesi sonucunda oluşturulan kuramsal çerçeve Şekil 4'de görülmektedir (Scobie ve Persaud, 2010).




Şekil 4: Hastaların Hasta Güvenliği Sürecine Katılımları İçin Önerilen Kuramsal Çerçeve (Scobie ve Persaud, 2010)

Şekil 4'te görüldüğü gibi, hastaların hasta güvenliği sürecine katılmalarındaki engeller azaltılıp kolaylaştırıcı unsurlardan faydalanıldığ takdirde hem hastaların öz yeterliliği artacak hem de hasta-hizmet sunucu işbirliği ile birlikte hasta güvenliğinin etkinliği sağlanmış olacaktır.

\section{HASTA KATILIMININ AVANTAJLARI VE ZORLUKLARI}

Hastaların sağlık hizmetlerine proaktif bir biçimde katılımlarının sağlık hizmetlerinin kalitesine katkıda bulunduğu ve çok az sayıda risk teşkil ettiği düşünülmektedir. Değişen sağlık anlayışı kapsamında hastaların karar alma sürecindeki rolü gün geçtikçe daha fazla önem kazanmaktadır.

Hasta katılımının sağlayacağı avantajların yanı sıra uygulamada birtakım zorluklarla da karşılaşılmaktadır. Hasta katılımının avantajları ve zorlukları aşağıda belirtilmiştir (Bayın, 2016: 462; European Commission, 2012: 1213):

\section{Avantajlar1}

- Hastaların daha fazla motive edilmesi

- Klinik karar verme sürecinin iyileştirilmesi

- Hesap verilebilirlik sağlama

- Tedavi etkinliğinin artmas1

- Hizmet kalitesinin iyileştirilmesi

- Maliyetlerin azalt1lmas1

\section{Zorlukları}

- $\quad$ Etik konular

- Sağl1k profesyonellerinin desteğinin eksikliği

- Hastaların davranışları

- Hastaların bilgi ve farkındalığının yetersizliği

- Güvenlik ve temsiliyet endişeleri

\section{SONUÇ VE ÖNERILER}

Günümüzde bireylerin sağlık hizmetleri ile etkileşimleri, sağlık alanındaki araştırmalarının başlıca odak noktası olarak kabul edilmektedir. Bireylerin sağlık hizmetlerine ihtiyaç duyup duymadıklarına ve buna ne zaman ihtiyaç duyduklarına, ihtiyaçlarını hangi planlar ve hizmet sunucularının 
karşıladığına, sağlıklarını nasıl yöneteceklerine, hizmet sunucuların ve sosyal çevrelerinin bazen çelişen tavsiyelerini nasıl idare edeceklerine karar vermeleri beklenmektedir. $\mathrm{Bu}$ artan sorumluluklar ve beklentileri değerlendirmek için araştırmacılar bireylerin bu ve diğer karar verme noktalarında nasıl bir katılım gerçekleştirecekleri hakkındaki anlayışı iyileştirmek için ekonomi, psikoloji, sosyoloji ve diğer alanlardan faydalanan bir dizi yöntem ve tasarım kullanmışlardır (Clancy, 2011: 389).

Sağlık hizmetlerinde hasta katılım sürecinin etkili ve verimli bir şekilde gerçekleştirilmesi için sağlık kurumları, sağlık profesyonelleri, politika yapıcılar ve sivil toplum kuruluşlarının aktif bir rol oynaması ve bu süreci desteklemeleri gerekmektedir. Hasta katılımının klinik süreçleri iyileştirme, maliyetleri azaltma, hasta memnuniyetinin artması ve daha kaliteli sağlık hizmeti verilmesi gibi yararlarının yanı sıra hastaların genel özelliklerinden ve sağlık profesyonellerinin yaklaşımından kaynaklanan zorlukları da bulunmaktadir.

Hasta katılım sürecindeki yararları artırmak ve karşılaşılan zorlukları azaltmak için öncelikle tüm paydaşların işbirliği yapmaları büyük önem taşımaktadır. Politika yapıcıların hasta katılım sürecini teşvik etmeleri ve bu yönde kararlar almasının, hizmet kalitesine ve toplumun sağlık seviyesinin yükselmesine katkı sağlayacağı söylenebilir. Sağlık kurumlarının hastane bilgi sistemlerinin hasta katılım sürecine uygun bir şekilde dizayn etmesi, hastaların etkili ve verimli sağlık hizmetleri alabilmelerine yönelik tedavi planları geliştirmeleri ve güçlü hasta katılımını teşvik etmelerinin faydalı olacağ1 düşünülmektedir. Bu kapsamda hasta eğitimine önem verilmesi, sağlık okuryazarlığının artması ve hastaların karar alma sürecine dahil ederek istek ve ihtiyaçlarının karşılanması hasta katılımının faydalarını çoğaltacağı düşünülmektedir. Sonuç olarak bakıldığında güçlü bir hasta katılımının gerek birey gerekse toplum sağlığını korumak ve geliştirmek için önemli bir rol oynamakta olduğu ve buna yönelik çalışmalar yapılması önerilmektedir.

\section{KAYNAKÇA}

ARDAHAN, M., ALP, F. Y. (2015), "Hasta Güvenliği ve Hasta Güvenliğini Sağlamada Sağlık Çalışanlarının ve Yöneticilerin Rolü", Acıbadem Üniversitesi Sağlık Bilimleri Dergisi, Cilt 6, S. 2, ss. 85-88.

ARMSTRONG, S. (2014), "The Patient Engagement Pyramid", (erişim adresi:http://blog.hellohealth.com/The-Patient-Engagement-Pyramid), (erişim tarihi: 07.02.2017). 
ATHENAHEALTH (2014), "5 Elements of a Successful Patient Engagement Strategy", (erişim adresi:

http://www.athenahealth.com/whitepapers/patient-engagement-strategies), (erişim tarihi: 07.02.2017).

BAYIN, G. (2016), "Sağlık hizmetlerinin geliștirilmesi sürecinde hasta ve toplum katılımının rolü", TAF Preventive Medicine Bulletin, Cilt 15, S. 5, ss. 458-466.

CARMAN, K. L., DARDESS, P., MAURER, M., SOFAER, S., ADAMS, K., BECHTEL, C., SWEENEY, J. (2013), "Patient and Family Engagement: A Framework for Understanding the Elements and Developing Interventions and Policies", Health Affairs, Volume 32, Issue 2, pp. 223-231.

CENTER FOR ADVANCING HEALTH (2010), "A New Definition of Patient Engagement: What is Engagement and Why is it Important?", (erişim adresi:

http://www.cfah.org/pdfs/CFAH_Engagement_Behavior_Framework_current.pdf), (erişim tarihi: 07.02.2017).

CLANCY, C. M. (2011), "Patient Engagement in Health Care", Health Services Research, Volume 46, Issue 2, 389-393.

DOMECQ, J. P., PRUTSKY, G., ELRAIYAH, T., WANG, Z., NABHAN, M., SHIPPEE, N., ..., ERWIN, P. (2014), "Patient Engagement in Research: A Systematic Review", $B M C$ Health Services Research, Volume 14, pp. 89.

EUROPEAN COMMISSION (2012), "Eurobarometer Qualitative Survey: Patient Involvement - Aggregate Report", (erişim adresi: http://ec.europa.eu/health/healthcare/docs/eurobaro_patient_involvement_2 012_en.pdf), (erișim tarihi: 07.02.2017).

FORBAT, L., HUBBARD, G., KEARNEY, N. (2009), "Patient and Public Involvement: Models and Muddles", Journal of Clinical Nursing, Volume 18, Issue 18, pp. 2547-2554.

GEE, R. E., CORRY, M. P. (2012), "Patient Engagement and Shared Decision Making in Maternity Care", Obstetrics \& Gynecology, Volume 120, Issue 5, pp. 995997.

OCLOO, J., MATTHEWS, R. (2016), "From Tokenism to Empowerment: Progressing Patient and Public İnvolvement in Healthcare İmprovement", BMJ Quality \& Safety, Volume 25, Issue 8, pp. 626-632.

PELleTiER, L. R., STICHLER, J. F. (2013), "Action Brief: Patient Engagement and Activation: A Health Reform Imperative and Improvement Opportunity for Nursing", Nursing Outlook, Volume 61, Issue 1, pp. 51-54.

PREY, J. E., WOOLLEN, J., WILCOX, L., SACKEIM, A. D., HRIPCSAK, G., BAKKEN, S., ..., VAWDREY, D. K. (2014), "Patient Engagement in the Inpatient Setting: A Systematic Review", Journal of the American Medical Informatics Association, Volume 21, Issue 4, pp. 742-750.

SCOBIE, A. C., PERSAUD, D. D. (2010), "Patient Engagement in Patient Safety: Barriers and Facilitators", Patient Safety \& Quality Healthcare, Issue 7, pp. 4247.

SUlliVAN, P., GOLDMANN, D. (2011), "The Promise of Comparative Effectiveness Research",Jama, Volume 305, Issue 4, pp. 400-401.

TANG, P. C., NEWCOMB, C. (1998), "Informing Patients", Journal of the American Medical Informatics Association, Volume 5, Issue 6, pp. 563-570.

WASSON, J., COLEMAN, E. A. (2014), "Health Confidence: An Essential Measure for Patient Engagement and Better Practice", Family Practice Management, Volume 21, Issue 5, pp. 8-12. 
